\title{
Fibrotic Lesion Indicator
}

National Cancer Institute

\section{Source}

National Cancer Institute. Fibrotic Lesion Indicator. NCI Thesaurus. Code C161484.

An indication as to whether a fibrotic lesion is present. 